\title{
Spatial distribution and functional significance of leaf lamina shape in Amazonian forest trees
}

\author{
A. C. M. Malhado ${ }^{1, * * * *}$, R. J. Whittaker ${ }^{1, * * *}$, Y. Malhi ${ }^{1, * * *}$, R. J. Ladle ${ }^{1, * * *}$ H. ter Steege ${ }^{2, * * *, * * * *}$, N. Butt ${ }^{1, * * *}$, \\ L. E. O. C. Aragão, ${ }^{1 * * *}$, C. A. Quesada ${ }^{3, * * *}$, A. Murakami-Araujo ${ }^{4, * * *}$, O. L. Phillips ${ }^{3, * * *, * * * *}$, J. Peacock $^{3, * * *}$, \\ G. López-González ${ }^{3, * * *}$, T. R. Baker ${ }^{3, * * *}$, L. O. Anderson $^{1, * *}$, L. Arroyo $^{4, * * * *}$, S. Almeida ${ }^{5, * * *}$, N. Higuchi $^{6, * * * *}$, \\ T. J. Killeen ${ }^{7, * * *}$, A. Monteagudo ${ }^{8, * * *}$, D. A. Neill ${ }^{9, * * *}$, N. C. A. Pitman ${ }^{10, * * *}$, A. Prieto $^{11,{ }^{* * * *}}$, R. P. Salomão ${ }^{5 * * * *}$, \\ R. Vásquez-M..$^{8 * * *}$, W. F. Laurance ${ }^{6, * * *}$, and H. Ramírez A. ${ }^{12, * * *}$ \\ ${ }^{1}$ School of Geography and the Environment, Oxford University, UK \\ ${ }^{2}$ Dept. of Plant Ecology and Biodiversity, Utrecht University, The Netherlands \\ ${ }^{3}$ Earth and Biosphere Institute, School of Geography, University of Leeds, UK \\ ${ }^{4}$ Museo Noel Kempff Mercado, Santa Cruz, Bolivia \\ ${ }^{5}$ Museu Paraense Emilio Goeldi, Belem, Brazil \\ ${ }^{6}$ Instituto National de Pesquisas Amazônicas, Manaus, Brazil \\ ${ }^{7}$ Center for Applied Biodiversity Science, Conservation International, Washington, DC, USA \\ ${ }^{8}$ Herbario Vargas, Universidad Nacional San Antonio Abad del Cusco, Cusco, Perú \\ ${ }^{9}$ Herbario Nacional del Ecuador, Quito, Ecuador \\ ${ }^{10}$ Center for Tropical Conservation, Duke University, Durham, USA \\ ${ }^{11}$ Instituto de Investigación de Recursos Biológicos Alexander von Humboldt, Colombia \\ ${ }^{12}$ INDECOR, Facultad de Ciencias Forectales, Universidad de Los Andes, Venezuela \\ * now at: Universidade Federal de Viçosa - UFV, Av. P. H. Rolfs, S/N. Centro Viçosa, MG, 36570-000, Brasil \\ ** Conceived the study, collected leaf data, undertook the analysis, and wrote manuscript. \\ *** Orientated, reviewed and improved manuscript. \\ **** Contributed data.
}

Received: 18 December 2008 - Published in Biogeosciences Discuss.: 9 February 2009

Revised: 17 June 2009 - Accepted: 3 August 2009 - Published: 10 August 2009

\begin{abstract}
Leaves in tropical forests come in an enormous variety of sizes and shapes, each of which can be ultimately viewed as an adaptation to the complex problem of optimising the capture of light for photosynthesis. However, the fact that many different shape "strategies" coexist within a habitat demonstrate that there are many other intrinsic and extrinsic factors involved, such as the differential investment in support tissues required for different leaf lamina shapes. Here, we take a macrogeographic approach to understanding the function of different lamina shape categories. Specifically, we use 106 permanent plots spread across the Amazon rainforest basin to: 1) describe the geographic distribution of some simple metrics of lamina shape in plots from across Amazonia, and; 2) identify and quantify relationships between key environmental parameters and lamina shape in tropical forests. Because the plots are not randomly distributed across the study area, achieving this latter objective
\end{abstract}

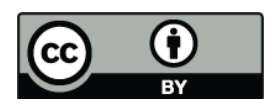

Correspondence to: A. C. M. Malhado (anaclaudiamalhado@gmail.com) requires the use of statistics that can account for spatial autocorrelation. We found that between $60-70 \%$ of the 2791 species and 83908 individual trees in the dataset could be classified as having elliptic leaves (= the widest part of the leaf is on an axis in the middle fifth of the long axis of the leaf). Furthermore, the average Amazonian tree leaf is 2.5 times longer than it is wide and has an entire margin. Contrary to theoretical expectations we found little support for the hypothesis that narrow leaves are an adaptation to dry conditions. However, we did find strong regional patterns in leaf lamina length-width ratios and several significant correlations with precipitation variables suggesting that water availability may be exerting an as yet unrecognised selective pressure on leaf shape of rainforest trees. Some support was found for the hypothesis that narrow leaves are an adaptation to low nutrient soils. Furthermore, we found a strong correlation between the proportion of trees with non-entire laminas (dissected, toothed, etc.) and mean annual temperature once again supporting the well documented association that provides a basis for reconstructing past temperature regimes. 


\section{Introduction}

Leaves come in a huge variety of shapes and sizes, from needle-like spikes to almost perfect disks. However, as with many other leaf traits, it is not straightforward to assign adaptive function to a particular leaf shape because the form of the lamina represents a solution to the complex "problem" of optimising light capture and water loss while minimising unnecessary energy expenditure in the production of leaf support structures. Herbivores may also have a significant influence on leaf shape and size although the exact nature of this causal relationship has remained elusive (Brown et al., 1991). For example, certain leaf shapes might act as physical barriers to insect herbivory or influence the density or diversity of herbivores attacking a leaf (Rivero-Lynch et al., 1996).

The importance of support tissues in determining leaf shape is clearly illustrated by the strong patterns of association between different leaf shapes and vascular patterns and biomass investments in vasculature (Dengler and Kang, 2001; Kessler and Sinha, 2004). Of particular importance in this respect is the distribution of leaf mass from the base to the tip of a leaf that, in turn, has an important influence on the amount of investment in support tissues (Niinemets et al., 2007). For example, an obovate (egg-shaped) leaf, in which the majority of the weight of the leaf is situated far from the leaf base, requires a far greater investment in supporting tissues than a cordate (heart-shaped) leaf, where the inverse occurs. Givnish and Vermeij (1976) have argued that the higher proportion of cordate leaves on vines in forests in Costa Rica is evidence of how this shape is more likely to evolve when investment in woody support tissue is not required.

If we consider a leaf lamina ( $=$ the expanded portion or blade of a leaf) purely in terms of the optimisation of water supply to tissues and the amount of biomechanical support for a given biomass investment in the mid-leaf then we would expect all leaves to be approximately wedge-shaped (Givnish, 1978). That they are not is clear evidence that other selective pressures and trade-offs also play an important role in determining leaf shape in many species. Indeed, Givnish (1978) speculated that wedge-shaped leaves are not well designed to be efficiently packed on a stem. Furthermore, and possibly more significantly, self-shading is predicted to be higher when the light-intercepting area of the leaf is closer to the axial support, as occurs in more wedge-shaped leaves (Horn, 1971; Pearcy and Yang, 1998; Pearcy et al., 2005; Niinemets et al., 2007).

Hence a compromise between the opposing factors of biomechanical support and minimizing self-shading suggests that an elliptical or similar shape would tend to be an optimal shape. Although hard to demonstrate in the field due to the difficulties of measuring light capture of a leaf, this prediction was conceptually confirmed by Takenaka (1994), who used a computer simulation to study the possible effects of the length-to-width ratio of a leaf blade and petiole length on shoot light capture. The simulation predicted that higher length-to-width ratios and longer petioles increased light capture per unit leaf area due to a reduced aggregation of leaf area around the stem. Interestingly, Takenaka's (1994) study also suggested that when the light shines from predominantly higher angles, such as is experienced by leaves in the understorey, narrow laminas would be favoured.

Lamina shape, through boundary layer effects, is also thought to have a strong effect on transpiration and photosynthesis under certain environmental conditions (Givnish and Vermeij, 1976; Givnish, 1978, 1979, 1984). Theory predicts that broader leaves have a thicker boundary layer of slowmoving, non-turbulent air and slower convective heat loss and therefore tend to be hotter than ambient air temperature when exposed to net incoming radiation. All other things being equal, broad leaves will therefore tend to be heated above air temperature by a wider margin than narrow leaves. This can be disadvantageous, especially in areas where water is limiting, because it may lead to higher rates of respiration and decreased rates of photosynthesis (Lloyd and Farquhar, 2008) through the following mechanism: higher leaf temperatures cause a higher water vapour deficit that, in turn, leads to increased transpiration/water loss. The plant adaptively responds to this by closing stomata, which has the net effect of reducing $\mathrm{CO}_{2}$ uptake and reducing the rate of photosynthesis. Higher-than-ambient leaf temperatures may be disadvantageous for the tree because respiration rates increase faster with increasing temperature than do rates of photosynthesis. In addition, higher surface temperatures will result in higher surface water vapour deficit thereby, increasing rates of both transpiration and water loss.

This elevated temperature effect should be more important for leaves experiencing strong solar radiation, and where water is in short supply (since transpiration is also an effective mechanism for shedding heat). These environmental pressures are predicted to influence the evolution of both leaf size and shape in as much as the increased water acquisition costs in dryer areas are predicted to favour smaller, narrow leaves (Givnish, 1978, 1979, 1984). This theory has relatively strong empirical support - it is well known that leaf size tends to decrease toward dry, sunny, or nutrientpoor habitats (Raunkiaer, 1934; Webb, 1968; Givnish, 1984, 1987). However, it should be noted that such correlations are highly scale dependent (Cunningham et al., 1999).

Leaf laminas do not just vary in terms of length and width. Many leaves, especially in trees from temperate climates, also have distinct lobes or serrations, and some blades are almost completely dissected. Lobing and leaf dissection may be an important adaptation for reducing self-shading and may even play a role in spreading light to surrounding leaves (Horn, 1971). Once again, technical limitations have made it difficult to study light capture under field conditions although the results of computer simulations suggest that while lobing per se is not advantageous for light interception, the combined effect of lobing along the length of a stem may have a 
significant influence on overall light interception of the plant (Niklas, 1997). Departures from a complete leaf margin may also influence water dynamics. For example, dissected leaves (deeply cut or divided blades) are associated with increased water loss and, by extension, may be less adaptive under low rainfall conditions or higher temperatures. More generally, palaeoecological evidence suggests that the evolutionary response of trees to warmer temperatures has been to produce leaves with fewer teeth, smaller tooth area, and lower degree of blade dissection (Royer and Wilf, 2006).

The functional basis of reductions in leaf size and width in areas of low nutrient soil (Cunningham et al., 1999; Fonseca et al., 2000) is less clear than the similar association with lower rainfall (McDonald et al., 2003). Rodriguez et al. (1998) suggest that low nutrient soils favour a reduction in leaf area per se on the basis that leaves with a smaller surface area should be favoured because of the slower growth of plants on infertile soils. Alternatively, Yates et al. (2008) suggest that the smaller boundary layer of narrow leaves allows higher transpiration rates when water is plentiful and, in the case of the fynbos flora of South Africa is an adaptation for nutrient uptake during winter, and may also provide a benefit associated with the improved coupling of leaf to ambient temperature during the summer drought period.

Leaf lamina shape is clearly a challenging trait whose evolution has been influenced by several distinct ecological and physical attributes of the environment in addition to various physical and physiological trade-offs. It is also obvious that leaf shape plays a crucial role in determining the light capture efficiency and hence the rate of carbon conversion of a plant. Although many studies (see above) of leaf shape have concentrated on small scale experimental studies or computer simulations, significant insights into its adaptive significance may also be gained through adopting a macrogeographic approach that seeks statistical associations between different shape metrics and environmental parameters. This approach has a long history in botany and palaeontology where the relationship between leaf shape and climate factors has been intensively studied in some ecosystems.

Macrogeographic studies have recently become possible in tropical forests with the construction of large interlinked databases of permanent plots. In this paper we use the RAINFOR database of permanent plots (Peacock et al., 2007) to: 1) describe the geographic distribution of some simple metrics of lamina shape in plots from across Amazonia, and; 2) identify and quantify relationships between key environmental parameters and leaf shape in tropical forests. Specifically, we systematically examine qualitative and quantitative variation in lamina shape across the Amazon basin and address the following hypotheses:

i) Leaves from the Amazon basin conform to the typical distribution of lamina shapes observed in other rainforests. Namely, they are predominantly entire- margined with an ovate-elliptical shape, and roughly three times long as broad.

ii) The proportion of trees in a plot with relatively narrow leaves (thereby limiting water loss) increases in areas of relatively low rainfall.

iii) The proportion of trees in a plot with relatively narrow leaves is greater in areas of relatively low nutrient soils.

iv) The proportion of leaves with non-entire margins (dissected, toothed, etc.) is inversely correlated with mean annual temperature (Givnish, 1987; Traiser et al., 2005).

\section{Methods}

\subsection{Database construction}

Our main source for exploring spatial variation in leaf shape across the Amazon rainforest is the RAINFOR database (Peacock et al., 2007 ${ }^{1}$ ), which has been constructed using information from 115 permanent plots distributed across eight South American countries, to which we added 26 data plots from Guyanas and Suriname compiled by the ATDN network (ter Steege et al., 2003). At the time of data extraction for this study (August 2006) the RAINFOR database contained 108720 individual trees $\geq 10 \mathrm{~cm} \mathrm{DBH}$ (diameter at breast height) from 3324 species. The plots used in this study spanned local and regional environmental gradients that naturally occur in Amazonia, including mature forests that are seasonally flooded, water-logged, and non flooded lowland terra firme forests (90\% of plots) on both clay-rich and white-sand substrates. All sites consisted of apparently mature forest with natural gap-phase dynamics and a canopy dominated by non-pioneer species and, furthermore, none of the plots is believed to have experienced any recent humancaused disturbance. It is important to note that not all data were available for all plots - plots lacking relevant environmental data were removed from certain analyses. Furthermore, 35 plots were excluded from plot-based analyses because they had $>30 \%$ of trees that were either unidentified at species level or for which herbaria/flora data were not available. The individual plots $(n=106)$ used in this study range in size from 0.25 to $9 \mathrm{ha}$ (mean $\pm \mathrm{SD}=1.1 \pm 1$ ha; median $=1$ ha) and in total encompass 116.9 ha of forest. The number of stems per plot (including undetermined stems) ranged from 265 to 1168 per ha (mean $\pm \mathrm{SD}=651 \pm 156$ ).

\subsection{Quantifying leaf shape}

Approaches for quantifying leaf shape can be split into two broad classes: those using categorical, primarily qualitative shape categories (e.g. elliptical, obovate, rectangular, etc.)

\footnotetext{
${ }^{1}$ http://www.rainfor.org
} 
and those describing shape as ratios or other abstract mathematical descriptors (such as perimeter-to-area or length-towidth ratio). Both classes of approach have limitations and it is hard to compare one to another. Here we use combinations of the two approaches in an attempt to effectively "capture" the most ecologically important aspects of leaf lamina shape. To easily distinguish between the two types of measurement in the analysis we use the following notation: qualitative leaf shape category = "shape ${ }_{C A T}$ "; quantitative leaf shape in$\operatorname{dex}=$ " $I$ ". More sophisticated methods based on techniques such as eigenvector analysis are currently being applied to leaf shape analysis (e.g. Krieger et al., 2007) but were inappropriate for the present study since the only source of available data for the vast majority of species were low resolution specimen images from herbaria and floras.

We used two different systems of increasing sophistication for assigning leaves to qualitative categories. Our initial description of the qualitative shape characteristics ( shape $_{\mathrm{CAT} 1}$ ) of our sample population was achieved by assigning specimen images with one of 18 qualitative leaf shape categories used by the Royal Horticultural Society Dictionary (1997). Although crude, this system was deemed to be an effective way to provide a general characterization of leaf shape in Amazonia. Through this method we categorized 2791 species and only excluded undetermined species (475 species) or species where specimen images were not currently available (60 species). In total, data for 83868 individual trees and 2791 species were available for analysis. Leaflets from species with compound leaves were considered as the unit of study. The following 18 ordinal categories were used in the analysis (Fig. 1): 1) bi-falcate-lobed, 2) bilobed, 3) falcate, 4) flabellate, 5) lanceolate, 6) linear, 7) obcordate, 8) oblanceolate, 9) obovate, 10) orbicular, 11) oval, 12) ovate, 13) palm-lobed, 14) reniform, 15) rhomboidal, 16) tri-lobed, 17) oblong, and 18) elliptic.

For our second shape categorisation system (shape ${ }_{\mathrm{CAT} 2}$ ) we followed the assignment system suggested by the Leaf Architecture Working Group (1999), in which they describe the overall shape of the lamina based on the localization of the greatest width perpendicular to the axis of greatest length. This results in the following shapes (Fig. 2): 1) ovate: widest part is in the basal 2/5,2) elliptic: the widest part of a leaf is on an axis in the middle fifth of the long axis of the leaf, 3) obovate: widest part is on the apical $2 / 5$, and 4) oblong: widest part is a zone in the middle $1 / 3$ of the long axis where the opposite margins are roughly parallel.

This latter system creates less space for assessment bias but also gives less flexibility for describing the range of observed leaf shapes. We also attempted to reduce variability caused by the subjective and qualitative nature of the leaf shape categorization process by restricting the assessment of all images retrieved from floras and herbaria to a single person - in this case the lead author.

For our quantitative measurement system we decided to use the simplest ratio-based index $\left(I_{1}=\right.$ maximum leaf

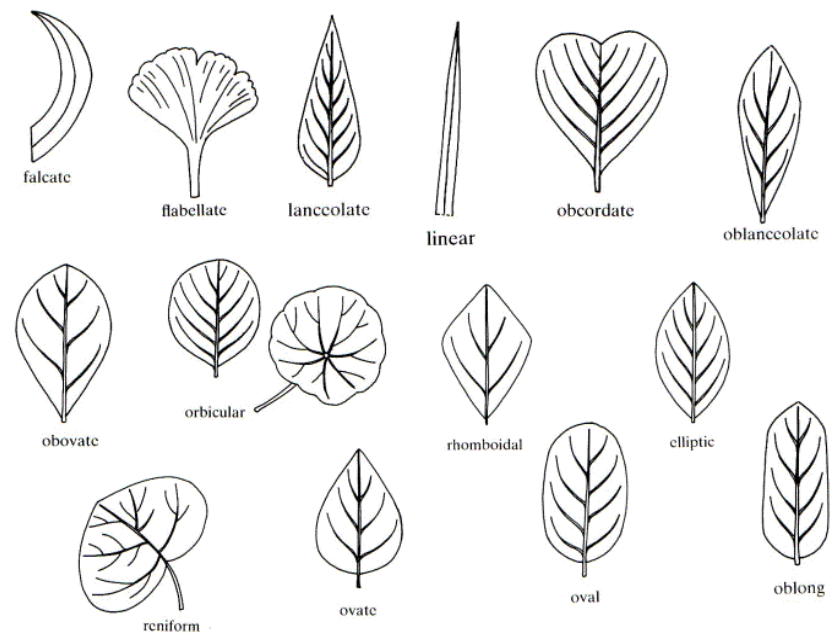

Fig. 1. Categorization system derived from the Royal Horticultural Society Dictionary (1997). The figure shows 14 ordinal categories (the four lobed categories are not shown).

length/maximum leaf width) for three reasons: first, this is an exceedingly common metric that has been used in many studies and therefore would aid in comparison with the literature. Second, some of the leaf specimen images used for this project did not have accurate scales (although size categories were available for the vast majority of specimens, Malhado et al., 2009), and a ratio metric such as the one chosen is necessarily size independent. Finally, the images were often of relatively low resolution and some specimens were of poor quality. In cases such as these a simple index still allows an adequate metric where a more sophisticated method might be restricted. Since the tip often makes up a significant proportion of the total length, especially in rainforest trees that frequently possess elongated acuminate tips, we perform all analyses using both total length and total length minus the tip section of the leaf $\left(=I_{2}\right)$. It should also be noted that we were unable to get a suitable image to calculate the shape index for a few species and the sample size is therefore slightly lower (2680 species, 75010 individuals) than for the shape categories (above).

The length-width index is not straightforward to interpret. For example, if we were to use only the mean $I_{1,2}$ for each plot important trends may be missed because plots with different length-width distributions could display similar means. Thus, for the purpose of illustration and analysis, we follow the methodology of Traiser et al. (2005), and divide our leaf shape index into three ordinal categories: leaves with an index of $\leq 1$, between 1 and $<3$, and leaves with an index $\geq 3$. One of the aims of using these ordinal categories is to identify the distribution and potential environmental correlates of leaves at either end of the leaf shape continuum (broad $\rightarrow$ elongate). Traiser et al.'s (2005) categories may not do this effectively in the present study because they are based on European vegetation. For this reason, we also split the 

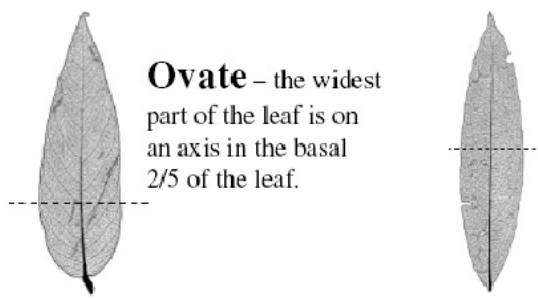

Elliptic - the widest part of the leaf is on the axis in the middle fifth of the long axis of the leaf.

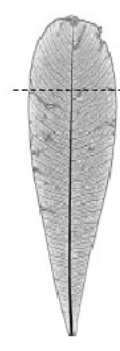

Obovate-the widest part of the leaf is on an axis in the

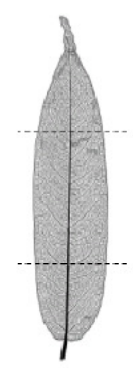

Oblong - the widest part of the leaf is a zone in the middle $1 / 3$ of the long axis where the opposite margins are roughly parallel apical $2 / 5$ of the leaf.

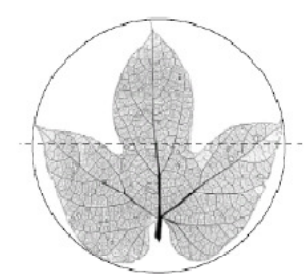

Elliptic (lobed) - in lobed leaves the blade shape is determined from an ellipse drawn around the apices of the lobes. The widest part of the ellipse is then considered as in unlobed leaves.

Fig. 2. Leaf Architecture Working Group (1999) categorization system.

dataset based on the mean ratio of length to width for the sample. Broader leaves (in an Amazonian context) are defined as those with a length to width ratio below one standard deviation of the mean. Conversely, narrower leaves are defined as those with a length to width ratio above one standard deviation of the mean. We derived the mean from lengthwidth ratios of all species in our study using measurements that both incorporated and removed the contribution of the leaf tip ( $I_{1,2}$ data reported in the result section). These metrics are labelled $I_{1,2, b}$ and $I_{1,2, n}$ respectively. Finally, we created a compound index of relative narrowness of leaves within a plot $\left(I_{1,2, \text { comp }}=I_{1,2, n}-I_{1,2, b}\right)$.

Leaf size and shape may covary with each other and with other physical or physiological characteristics of the tree (Brown et al., 1991) - this may be especially true of very small leaves where biomechanical tradeoffs relating to the production of support structures become less relevant. Furthermore, it has already been shown (Malhado et al., 2009) that the proportion of large-leaved species in the RAINFOR database decreases with some metrics of water availability. Thus, in order to control for the potential covariance between leaf size and leaf shape a sub-set of the data that included only trees with large leaves (those in mesophyll, macrophyll, and megaphyll categories - sensu Webb, 1959) was analyzed separately.
We also characterized leaves in terms of whether the margin of the lamina is entire (= smooth and without teeth, Leaf Architecture Working Group, 1999) or had some form of teeth or serration (serrate, crenate, serrulate, incised).

\subsection{Geographical distribution of leaf shape}

We investigated the spatial distribution leaf lamina through simple comparisons of leaf shape metrics (shape CAT1 $_{1}$, shape $\left._{\text {CAT2 }}, I_{1,2}\right)$ at a regional level (Table 1). In previous studies of leaf function in Amazonia using the RAINFOR database (e.g. Malhado et al., 2009) we found consistent differences in leaf characteristics among four main regions: Region 1, North Amazonia, containing plots from Guyanas, Suriname and Venezuela; Region 2, Northwest Amazonia, containing plots from Ecuador, Colombia, and North Peru; Region 3, Central and East Amazonia, all Brazilian plots (states of Amazonas and Pará only); Region 4, Southwest Amazonia, containing plots from Bolivia and South Peru.

\subsection{Leaf shape - environmental correlations}

We also made a detailed investigation of the potential associations between certain environmental parameters and leaf lamina shape data. The environmental parameters (independent variables) chosen for our model (annual rainfall, standard deviation of monthly rainfall, maximum climatological water deficit (MWD; mm), and the length of the dry season, see Fig. 1, Malhado et al., 2009, in accompanying paper in this volume) reflect a combination of some of the main environmental variables that are thought to influence the evolution of different lamina shapes and the limited number of data sources that are currently available for macrogeographic analysis of Amazonia. We used a time-series (1998-2005) of monthly rainfall derived from the Tropical Rainfall Measuring Mission (TRMM 3B43-V6) at $0.25^{\circ}$ spatial resolution (following Malhado et al., 2009). We tested the hypothesis that the proportion of non-entire margins is negatively correlated with ambient temperature using annual mean temperature $\left({ }^{\circ} \mathrm{C}\right)$ data retrieved from the weather-station interpolated BIOCLIM (Bioclimate Prediction System climate database ${ }^{2}$, Hijmans et al., 2005). As weather stations are sparsely distributed across Amazonia, the satellite-based TRMM provides spatially comprehensive rainfall data and BIOCLIM provides comparable temperature data.

It should also be recognised that the seven year climate series represents a small sample of current climate, and may not necessarily represent the historical environments within which the tree species evolved. Here, we make the assumption that current climate provides a sufficient approximation of historical climate to pick up any strong environment-trait correlation. However, due to this assumption we would advise a cautious approach to the interpretation of these results.

\footnotetext{
${ }^{2}$ www.worldclim.org/bioclim.htm
} 
Table 1. Overview of variables used in this study. The qualitative variables are: the 18 nominal categories from the Royal Horticultural Society (Shape ${ }_{\mathrm{CAT} 1}$ ); the 4 nominal Leaf Architecture Working Group categories (Shape ${ }_{\mathrm{CAT} 2}$ ); and lamina margin classification (Margin). The length-width ratio of a leaf $\left(I_{1}\right)$ and the length-width ratio of a leaf without leaf tip $\left(I_{2}\right)$ are the basis for the quantitative variables. Different metrics are used on the quantitative analyses: the mean values for the $I_{1,2}$; proportion of trees following Traiser's et al. (2005) categories; and proportion of broad/narrow leaves in relation to the Amazonian context (see Methods). In addition, we also used a shape variable controlling for the leaf size category. Analyses were performed in three main groups: 1) general description of the data/patterns (descriptive), 2) study of the regional variation of lamina shape (regional distribution), and 3) study of correlations between lamina shape and environmental variables (environmental correlations).

\begin{tabular}{lcccc}
\hline & Descriptive & $\begin{array}{c}\text { Regional } \\
\text { distribution }\end{array}$ & $\begin{array}{c}\text { Environmental } \\
\text { correlations }\end{array}$ & Source \\
\hline Qualitative & & & & Royal Horticultural Soc. \\
\hline shape $_{\text {CAT1 }}$ (18 categories) & $\checkmark$ & & & Leaf Architecture Working group \\
shape $_{\text {CAT2 }}$ (4 categories) & $\checkmark$ & $\checkmark$ & & Leaf Architecture Working group \\
Margin (entire/not entire) $_{\text {Quantitative }}$ & $\checkmark$ & $\checkmark$ & $\checkmark$ & \\
\hline$I_{1}$ (mean) & & & $\checkmark$ & Traiser et al. (2005) \\
$I_{2}$ (mean) & $\checkmark$ & $\checkmark$ & $\checkmark$ & Original \\
$I_{1,2}(\leq 1,1-3, \geq 3)$ & $\checkmark$ & $\checkmark$ & $\checkmark$ & Original \\
$I_{1,2}<1$ SD=I $1,2, b>1 \mathrm{SD}=I_{1,2, n}$ & & $\checkmark$ & $\checkmark$ & \\
$I_{1,2, \text { comp }}$ & & $\checkmark$ & $\checkmark$ & \\
$I_{1,2}$ (only big leaves) & & $\checkmark$ & & \\
\hline
\end{tabular}

In the regressions, we used a range of dependent variables derived from our alternative ways of quantifying lamina shape. These variables are (Table 1): the means of length-width ratios (mean $I_{1,2}$ ); the proportions of individual trees falling into the three ordinal categories of Traiser et al. (2005); and the ordinal categories of broad and narrow lamina shapes defined by the mean and standard deviation of Amazonian length-width ratios $\left(I_{1,2, n} ; I_{1,2, b} ; I_{1,2, \text { comp }}\right)$.

Narrow leaves may also be an adaptation to nutrient poor soils. We therefore used data on soil fertility (sum of bases and phosphorus) when these data were available (23-44 plots, Quesada et al., 2009). Malhado et al. (2009) briefly explain the methodology for soil data and Quesada et al. (2009, in this Special Issue) provide an in-depth description of the data collection, analyses, and results.

\subsection{Statistical analysis}

This work follows the same statistical analyses and procedures described in Malhado et al. (2009) taking into account the spatial clustering of plots (Legendre and Legendre, 1998; Borcard et al., 2004; Diniz-Filho and Bini, 2005; Rangel et al., 2006; Dormann et al., 2007). Response variables are proportions and were transformed using an arcsin-square root transformation. Finally, statistically significant eigenvectors and climate metrics were entered as explanatory variables into standard OLS (ordinary least squares) regression models. Furthermore, we tested for an association between the sum of bases and phosphorus (plot soil fertility data) and lamina shape variables adjusting for the number of degrees of freedom using Dutilleul's (1993) method. All spatial analyses were performed using the software Spatial Analysis in Macroecology (SAM v2) (Rangel et al., 2006).

Trends in the distribution of lamina shape (see methods) in relation to the four Amazonian regions (regional analyses) were assessed using a one-way analysis of variance (ANOVA). These analyses were performed using SPSS 14.0.

\section{Results}

\subsection{Leaf shape characteristics of Amazonian trees}

Although leaf lamina shape varied considerably between species, and even within species found within the same plot, there is a strong tendency for Amazonian trees to possess leaves that are roughly elliptic (egg-shaped) to oblong. Based on our analysis (using shape CAT1 $_{\text {) }}$ of flora descriptions and herbarium specimens, among the 2791 identifiable species in the database $44.2 \%$ are elliptic, $22.1 \%$ oblong and $12.8 \%$ oval (Table 2 ). The least abundant shapes are flabellate $(0.04 \%$ of species) and obcordate forms $(0.04 \%$ of species). We also use this nominal categorization to describe 83908 individual trees in the dataset based on the specieslevel classification. Once again the most abundant form is elliptic (41.0\%) followed by oblong $(21.0 \%)$ and oval shapes (13.9\%) (Table 2). 
When categorized using the zone of the greatest width that lies perpendicular to the axis of the greatest length (shape ${ }_{\mathrm{CAT} 2}$ ), $67 \%$ of species possess elliptic lamina, $14 \%$ oblong lamina, $13.1 \%$ obovate lamina and $5.9 \%$ ovate lamina. The leaf shape distribution of individual trees follows the same overall pattern with elliptic leaves accounting for $68.8 \%$ of trees, oblong for $15.6 \%$, obovate for $11.8 \%$, and ovate for $3.9 \%$.

The quantitative analysis gives a mean length-width ratio with tip $\left(I_{1}\right)$ of $2.60 \pm 0.02$ (mean $\left.\pm \mathrm{SE}, \mathrm{SD}=0.91, n=2682\right)$ for species and $2.63 \pm 0.003$ (mean \pm SE, $n=75010$ ) for individual trees. The mean length-width ratio without tip $\left(I_{2}\right)$ is $2.47 \pm 0.02$ (mean $\pm \mathrm{SE}, \mathrm{SD}=0.88$ ) for species and 2.48 $\pm<0.001$ (mean \pm SE) for individuals. Hence, on average, the tip contributes to $5.8 \%$ of leaf length. The most abundant shape index category (sensu Traiser et al., 2005) are species and individuals with a ratio of greater than 1 and less than 3 that make up $77.96 \%$ of species and $78.47 \%$ of individuals of $I_{1}$ and similar proportions of $I_{2}$. Less than $0.3 \%$ of species and individuals had a $I_{1,2}$ of less than 1 (leaves wider than they are long). This proportion is very small because there are only six species in the database that possess a shape index of $\leq 1$. These six species (all from different families) with very wide, round leaves, tended to predominate in Region 4 (Southwest Amazonia). Although this seems like a potentially interesting result, this finding should be interpreted with caution due to the very low number of species involved. For the above reasons the results for these indices (Traiser et al., 2005) will only be briefly reported.

As predicted, lamina shape varies in relation to leaf size. There are significant differences between the lengthwidth ratios of species $(n=2651)$ in different size categories $\left(I_{1}-F=101.174, d f=5, \quad p<0.001 ; \quad I_{2}-F=118.292, d f=5\right.$, $p<0.001)$. The difference is driven by species with small leaves (leptophyll, nanophyll) possessing higher ratios than the other categories (microphyll, notophyll, mesophyll, and macrophyll).

Leaf shape categories (shape CAT2 ) are broadly distributed within and between taxonomic families. This is clearly illustrated by the proportion of families that contain species in four leaf shape categories $(23.2 \%)$, three leaf shape categories $(26.3 \%)$ or two leaf shape categories (20\%). Only $30 \%$ of the families were characterized by all of their species belonging to a single leaf shape category - however, the vast majority of these single-category families contained only one, two or three species.

The largest (most species rich) families (those with $>50$ species) in the sample showed similar distributions of species between the four leaf shape categories (shape $\mathrm{CAT2}_{\mathrm{C} 2}$ and, as for the entire dataset, the most abundant category was trees with elliptical leaves (Table 3). Three families deviated slightly from the general trend: Myristicaceae, Rubiaceae, and Sapotaceae, which seem to have a more even distribution of species between the four leaf shape categories (Table 3). Among the largest families, length-width ratio was
Table 2. Proportion of leaf lamina shape nominal categories $\left(\right.$ shape $\left._{\text {CAT1 }}\right)$ among Amazonian species $(n=2791)$ and trees $(n=83$ 868) present in the RAINFOR dataset. This categorization is derived from the Royal Horticultural Society Dictionary (1997) (Fig. 1).

\begin{tabular}{lrr}
\hline Leaf shape & Species $(\%)$ & Trees $(\%)$ \\
\hline Flabellate & 0.04 & 0.52 \\
Obcordate & 0.04 & 0.02 \\
5-lobed & 0.07 & 0.07 \\
Bi-lobed & 0.11 & 0.04 \\
Falcate & 0.18 & 0.13 \\
Rhomboidal & 0.18 & 0.11 \\
Tri-lobed & 0.18 & 0.04 \\
Reniform & 0.21 & 0.15 \\
Bi-falcate-lobed & 0.29 & 0.29 \\
Lanceolate & 1.15 & 0.62 \\
Orbicular & 1.29 & 1.44 \\
Linear & 1.72 & 8.17 \\
Oblanceolate & 3.80 & 3.05 \\
Ovate & 5.55 & 4.24 \\
Obovate & 6.09 & 5.25 \\
Oval & 12.76 & 13.89 \\
Oblong & 22.14 & 20.99 \\
Elliptic & 44.2 & 40.98 \\
\hline
\end{tabular}

also broadly consistent within and between families (Table 3). Annonaceae has the highest mean $I_{1}$ (around 3) followed by Myristicaceae, Burseraceae, Meliaceae, and Lauraceae. The lowest mean ratios (approximately 2.3) characterize the Rubiaceae, Euphorbiaceae, and Melastomataceae (Table 3). Among the largest (most species rich) families, only the Annonaceae presents an atypical distribution, with a relatively high mean length-width ratio.

The vast majority of Amazonian tree species in the database have entire leaves (98.8\%), and only $1.2 \%$ of the species possess non-entire margins - similar figures being found for individual trees.

\subsection{Regional variation in leaf shape}

Although variable, the average frequency of lamina shapeaxis (shape CAT2 $_{\text {) across }} 106$ plots is consistent with the following decrease in abundance gradient of lamina shape: elliptic, oblong, obovate and ovate (Fig. 3). When the plots were divided into four Amazonian regions (North Amazonia, Northwest Amazonia, Central and East Amazonia, and Southwest Amazonia) there is a significant difference among the regions in the frequency of individual trees with oblong leaves $(F=5.503, d f=3, p=0.002)$. Tukey's post-hoc test revealed that regions north and northwest have higher proportion of trees with oblong-shaped leaves than the other regions (central-east and southwest). 
Table 3. Leaf lamina shape physiognomy of the most species rich families ( $>50$ species) in the RAINFOR dataset. The first four columns present the distribution of the categorical lamina system (shape ${ }_{\mathrm{CAT} 2}$ : ovate, elliptic, obovate and oblong; the Leaf Architecture Working group), the three final columns represent the mean, the standard deviation and standard error of length-width ratios $\left(I_{1}\right)$.

\begin{tabular}{lrrrrrrr}
\hline & \multicolumn{7}{c}{ shape $_{\text {CAT2 }}$} \\
Families & Ovate & Elliptic & Obovate & Oblong & Mean & SD & SE \\
\hline Annonaceae & 4.8 & 66.9 & 8.3 & 20.0 & 3.14 & 0.93 & 0.08 \\
Apocynaceae & 4.0 & 74.7 & 14.7 & 6.7 & 2.45 & 0.61 & 0.07 \\
Burseraceae & 1.5 & 79.4 & 1.5 & 17.6 & 2.83 & 0.70 & 0.09 \\
Chrysobalanaceae & 1.7 & 76.7 & 3.4 & 18.1 & 2.40 & 0.54 & 0.05 \\
Clusiaceae & 18.6 & 60.0 & 14.3 & 7.1 & 2.40 & 0.52 & 0.06 \\
Euphorbiaceae & 13.0 & 64.0 & 10.0 & 13.0 & 2.37 & 0.61 & 0.06 \\
Fabaceae & 6.0 & 61.9 & 3.5 & 28.6 & 2.79 & 1.54 & 0.07 \\
Lauraceae & 2.3 & 78.9 & 13.7 & 5.1 & 2.82 & 0.80 & 0.06 \\
Lecythidaceae & 1.3 & 55.0 & 8.8 & 35.0 & 2.55 & 0.70 & 0.08 \\
Melastomataceae & 6.7 & 90.7 & 0.0 & 2.7 & 2.39 & 0.68 & 0.08 \\
Meliaceae & 0.0 & 58.8 & 13.7 & 27.5 & 2.83 & 0.57 & 0.08 \\
Moraceae & 5.9 & 61.8 & 11.8 & 20.6 & 2.56 & 0.65 & 0.06 \\
Myristicaceae & 5.9 & 33.3 & 9.8 & 51.0 & 2.88 & 0.68 & 0.10 \\
Myrtaceae & 4.2 & 86.1 & 6.9 & 2.8 & 2.67 & 0.64 & 0.07 \\
Rubiaceae & 6.1 & 66.1 & 23.5 & 4.3 & 2.34 & 0.66 & 0.06 \\
Sapindaceae & 4.7 & 76.6 & 10.9 & 7.8 & 2.76 & 0.70 & 0.09 \\
Sapotaceae & 0.0 & 58.2 & 35.5 & 6.4 & 2.52 & 0.52 & 0.04 \\
Overall mean & 5.1 & 67.6 & 11.2 & 16.1 & 2.6 & 0.7 & 0.07 \\
\hline
\end{tabular}

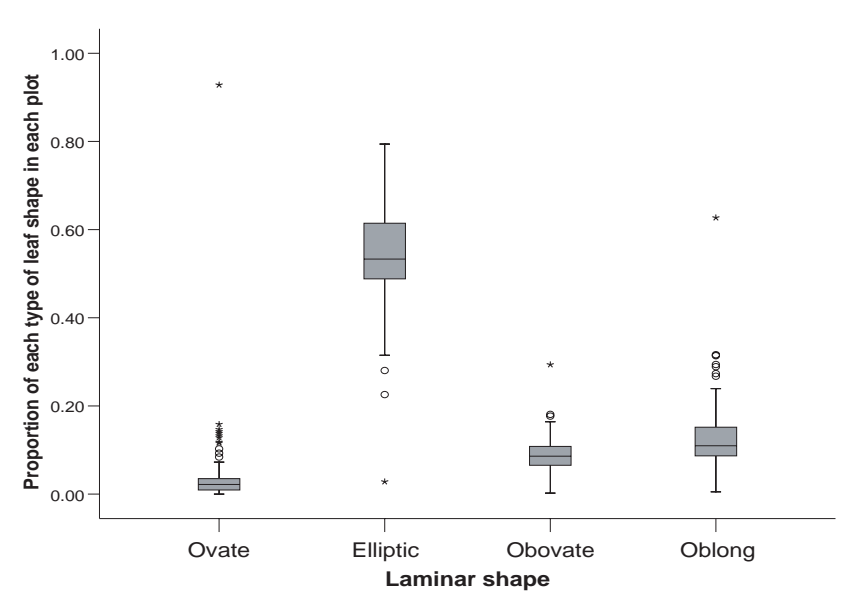

Fig. 3. Distribution of the abundance of lamina shape typesshape ${ }_{\text {CAT2 }}$ (elliptic, oblong, obovate and ovate) in 106 plots. This is calculated as the relative proportion of each lamina type in relation to the total of described lamina shapes within a plot. The top of each box represents the 75th percentile, the bottom represents the 25th percentile, and the line in the middle represents the 50th percentile (median). The whiskers represent the highest and lowest values that are not outliers or extreme values. Circles represent outliers and asterisks represent extreme values.
When we compare means of the quantitative shape indices per plot $\left(I_{1,2}\right)$ we find no significant difference across regions. However when the index is split into Traiser et al.'s (2005) categories there are regional differences in the proportion of trees with $I_{1,2}(\leq 1 ;>1$ and $<3$; and $\geq 3)$. These differences are being driven by plots in the north of the Amazon (Region 1) that have a higher proportion of trees in the "middle" shape index category $(>1$ and $<3)$.

Due to the arbitrary nature of Traiser et al.'s (2005) categorization (see Methods) an additional and more ecologically meaningful analysis was performed using two categories based on the proportion of plants falling outside 1 standard deviation of the mean of $I_{1,2}$ and a compound index representing the relative abundance of narrow or broad leaves within a plot (See methods). No significant regional differences are found for length-width ratio with tips $\left(I_{1, n}-F=0.145, d f=3, p=0.933 ; I_{1, b}-F=2.318, d f=3\right.$, $\left.p=0.080 ; I_{1, \mathrm{comp}}-F=0.703, d f=3, p=0.552\right)$. In contrast, significant regional differences are found between regions for the three length-width indices when tips are excluded from the measurements $\left(I_{2, n}-F=3071, d f=3, p<0.031\right.$; $I_{2, b}-F=2.758, d f=3, p<0.046 ; I_{2, \mathrm{comp}}-F=4.112, d f=3$, $p=0.008)$. These differences are being driven by trees in the south of Amazonia, a region (Fig. 4) displaying a lower proportion of narrow leaves than the other regions. Interestingly, this perceived distributional pattern changes when we control for the size of the leaf. The proportion of narrow-leaved trees ( $>1$ SD of the mean ratio) with big leaves (mesophyll 


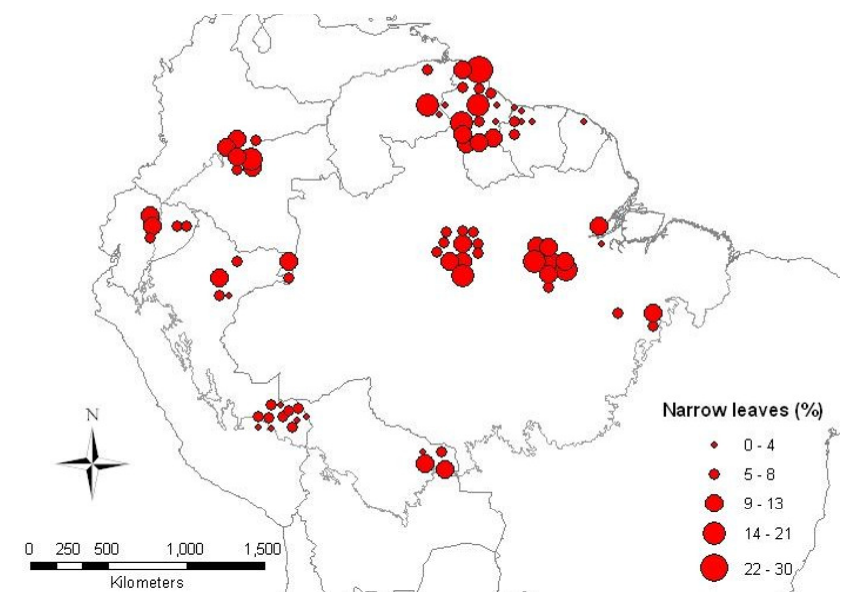

Fig. 4. Map of the proportion of relative narrow-leaves trees $\left(>1 \mathrm{SD}=I_{2, b}\right)$ in each plot organized by frequency categories. For the purposes of clear visualisation, the positions of some plots within clusters have been adjusted, and thus may not correspond to exact geographic location.

and above) is higher in Central Amazonia and Northwest Amazonia ( $\sim 8 \%$ and $\sim 7 \%$, respectively) in comparison with the northern region $(\sim 4 \%)$ and the southern region $(\sim 3 \%)$ (Fig. 5).

There are no significant difference in the proportion of non-entire margins across the four Amazonian regions $(F=2.129, d f=3, p=0.101)$.

\subsection{Leaf shape - environment correlations}

Several leaf shape metrics are significantly correlated with certain TRMM precipitation variables. For the Traiser's et al. (2005) categories, only the proportion of trees with a $I_{1,2, b}$ (broad, rounded leaves) is correlated with total precipitation, SD of total precipitation, and length of the dry season (Table 4). It is noteworthy that dry season length and total precipitation both appear to act in the same direction. However, as explained above, extreme caution should be taken in interpreting these results. More meaningfully, a significant correlation was also found between the proportion of narrow leaves (excluding tip) per plot $\left(I_{2, n}\right)$ and two precipitation variables, total precipitation and length of the dry season. Likewise a significant correlation was also observed between the compound shape index $\left(I_{2, \text { comp }}\right)$ and maximum water deficit (Table 4). Analyses of shape indices controlling for the size of the leaf (using the subset of the data with leaves of mesophyll or above) reveals significant correlations between relative proportion of narrow leaves ( $>1 \mathrm{SD}, I_{1,2}$ ) and all the TRMM variables (Table 5). No correlation is found for the proportion of non-entire margins and TRMM variables (Table 5), however, there is a significant (negative) correlation between mean annual temperature and proportion of leaves with non-entire margins (Table 6).

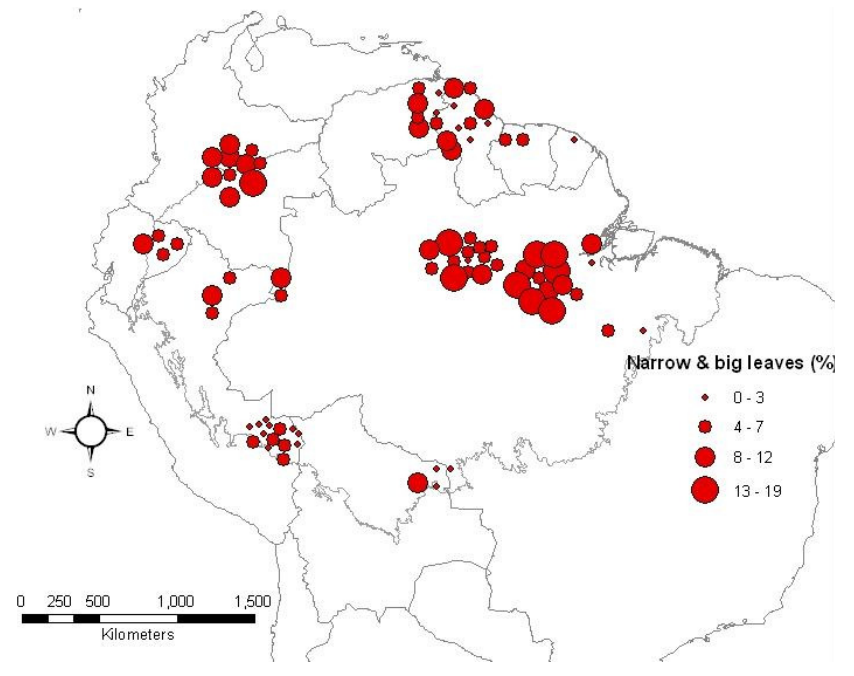

Fig. 5. Map of the proportion of narrow-leaved trees ( $>1$ SD of the mean) with big leaves (mesophyll and above) in each plot organized by frequency categories. For the purposes of clear visualisation, the positions of some plots within clusters have been adjusted, and thus may not correspond to exact geographic location

Distinct correlation patterns are also apparent between soil fertility and some quantitative leaf shape metrics. The proportion of trees with more rounded leaves $\left(I_{1,2}\right.$ of less than 1$)$ was positively correlated with sum of bases (Table 6) - once again this result should probably not be taken at face value due to the small number of individuals in this category. However, the proportion of trees with broad leaves $\left(I_{2, b}\right)$ was also positively correlated with sum of bases providing stronger support for this relationship. Furthermore, for both $I_{1}$ (with tips) and $I_{2}$ (without tips), there was a significant negative correlation between the compound index $\left(I_{1, \text { comp }}\right)$ and soil fertility/sum of bases (Table 6). Reinforcing this pattern, there are also two significant correlations between leaf shape and phosphorus data. The first one is a negative correlation with $I_{1, \text { comp }}$ and phosphorus. The second correlation is between proportion of narrow leaves and phosphorus when leaf size is controlled for (Table 6).

\section{Discussion}

The lamina of an average Amazonian tree leaf can be characterized as broadly elliptical, about 2.5 times longer than wide, and possessing an entire margin. Interestingly, this description is at slight variance with that reported in the literature in as much tropical tree leaves are typically said to be 3 times as long as wide (Leigh, 1975; Bongers and Popma, 1990). Furthermore, Bongers and Popma (1990) describe the general lamina shape as oblongate, and Turner (2001) as ovate-lanceolate - although this may be as much due to widespread variation in terminology as any substantive differences in shape. 
Table 4. OLS regression analysis of leaf lamina shapes of proportion of individual trees $\left(I_{1,2}\right)$ per plot in relation to environmental variables (Tropical Rainfall Measuring Mission, TRMM), controlling for spatial autocorrelation. Spatial structure was accounted for in all regressions by adding eigenvector filters produced with the Principal Coordinates of Neighbour Matrices (PCNM) method. These filters were omitted and 106 plots with measurements for all variables were used. Non-significant results using the Traiser et al. (2005) indices have been omitted.

\begin{tabular}{|c|c|c|c|c|c|c|}
\hline \multirow{3}{*}{ TRMM data } & \multicolumn{3}{|c|}{$I_{1}$} & \multicolumn{3}{|c|}{$I_{2}$} \\
\hline & \multicolumn{3}{|c|}{ Mean length-width ratio } & \multicolumn{3}{|c|}{ Mean length-width ratio } \\
\hline & Std. coeff. & $T$ & $p$ & Std. coeff. & $T$ & $p$ \\
\hline Total precipitation & -0.256 & -1.028 & 0.307 & -0.25 & -1.006 & 0.317 \\
\hline SD of total precipitation & 0.317 & 1.418 & 0.159 & 0.392 & 1.756 & 0.082 \\
\hline Maximum water deficit & -0.185 & -0.874 & 0.384 & -0.111 & -0.524 & 0.601 \\
\hline \multirow[t]{2}{*}{ Length of dry season } & -0.627 & -1.687 & 0.095 & -0.614 & -1.656 & 0.101 \\
\hline & \multicolumn{3}{|c|}{$\%$ trees $<1$} & \multicolumn{3}{|c|}{$\%$ trees $<1$} \\
\hline Total precipitation & -0.835 & -4.467 & $<0.001$ & -0.763 & -4.061 & $<0.001$ \\
\hline SD of total precipitation & 0.595 & 3.439 & $<0.001$ & 0.534 & 3.071 & 0.003 \\
\hline Maximum water deficit & 0.141 & 0.797 & 0.427 & 0.068 & 0.381 & 0.704 \\
\hline \multirow[t]{2}{*}{ Length of dry season } & -0.541 & -2.178 & 0.032 & -0.528 & -2.113 & 0.037 \\
\hline & \multicolumn{3}{|c|}{$\%$ trees in $I_{1, b}$} & \multicolumn{3}{|c|}{$\%$ trees in $I_{2, b}$} \\
\hline Total precipitation & -0.087 & -0.319 & 0.75 & 0.245 & 0.989 & 0.325 \\
\hline SD of total precipitation & -0.319 & -1.438 & 0.154 & -0.662 & -3.287 & 0.001 \\
\hline Maximum water deficit & -0.162 & -0.773 & 0.441 & -0.574 & -3.091 & 0.003 \\
\hline \multirow[t]{2}{*}{ Length of dry season } & 0.136 & 0.354 & 0.724 & 0.347 & 0.998 & 0.321 \\
\hline & \multicolumn{3}{|c|}{$\%$ trees in $I_{1, n}$} & \multicolumn{3}{|c|}{$\%$ trees in $I_{2, n}$} \\
\hline Total precipitation & -0.011 & -0.037 & 0.97 & 0.671 & 2.858 & 0.005 \\
\hline SD of total precipitation & 0.207 & 0.873 & 0.385 & -0.222 & -1.05 & 0.296 \\
\hline Maximum water deficit & -0.169 & -0.63 & 0.53 & 0.261 & 1.26 & 0.211 \\
\hline \multirow[t]{2}{*}{ Length of dry season } & -0.14 & -0.313 & 0.755 & 0.992 & 2.779 & 0.007 \\
\hline & \multicolumn{3}{|c|}{$I_{1, \mathrm{comp}}$} & \multicolumn{3}{|c|}{$I_{2, \text { comp }}$} \\
\hline Total precipitation & 0.218 & 0.864 & 0.39 & 0.419 & 1.827 & 0.071 \\
\hline SD of total precipitation & 0.088 & 0.388 & 0.699 & 0.083 & 0.4 & 0.69 \\
\hline Maximum water deficit & 0.229 & 1.076 & 0.285 & 0.514 & 2.693 & 0.008 \\
\hline Length of dry season & 0.226 & 0.598 & 0.551 & 0.636 & 1.843 & 0.068 \\
\hline
\end{tabular}

The predominance $(67 \%$ of species and $69 \%$ of individuals overall) of elliptic leaves in Amazonia supports the more geographically localized work of Schneider et al. (2003), who recorded elliptic leaves for $56-83 \%$ of species and $49-97 \%$ of individuals in eight altitudinal transects of mature Andean forest in Venezuela. More generally, the close concordance between the proportion of individual trees and species in different qualitative leaf size categories (for example Table 2) suggests that we can broadly estimate leaf trait abundance using species (alpha) diversity data.

The most species rich tree families in our sample followed a broadly similar pattern for the distribution of lamina shape categories to that of the whole dataset, with elliptic leaves typically predominating. One of the main exceptions to this pattern, the Myristicaceae, is in accordance with Gentry's (1996) description of the two most common genera having a strong tendency to possess oblong leaves. Similarly, the slightly higher proportions of obovate leaves observed in the Rubiaceae and Sapotaceae is broadly in line with previous descriptions (Verdcourt and Bridson, 1976) and field assessments in Amazonia (Ribeiro et al., 1999). The quantitative analysis of leaf shapes revealed a similar pattern of relative homogeneity within and between families - all families displaying mean length to width ratios of over $2: 1$. The relative homogeneity of leaf shapes in Amazonia supports the longstanding observation that leaves from unrelated trees within the same storey tend to be very similar in size and shape, making them hard to distinguish in the sterile condition (Richards, 1969).

\subsection{Regional patterns}

Several significant regional patterns were uncovered in the current study although their ecological interpretation is less straightforward than the studies described above. For example, higher proportions of trees with oblong-shaped leaves were found in the north and northwest as compared to other regions (central-east and southwest). Since this shape category can contain both broad and narrow oblong-shaped leaves it is difficult to make any strong inferences about potential function. However, even the seemingly clear result 
Table 5. OLS regression analysis of relative frequency of narrow leaves controlling for trees with large leaves and proportion of nonentire leaf margins of individual trees (MARGIN) in relation to TRMM (Tropical Rainfall Measuring Mission) variables, also controlling for spatial autocorrelation. Spatial structure was accounted for in all regressions by adding eigenvector filters produced with the PCNM (Principal Coordinates of Neighbour Matrices). These filters were omitted and 106 plots with measurements for all variables were used.

\begin{tabular}{|c|c|c|c|c|c|c|}
\hline \multirow{3}{*}{ TRMM data } & \multicolumn{3}{|c|}{ Large leaves and $I_{1}$} & \multicolumn{3}{|c|}{ Large leaves and $I_{2}$} \\
\hline & \multicolumn{3}{|c|}{$\%$ trees in $I_{1, n}$} & \multicolumn{3}{|c|}{$\%$ trees in $I_{2, n}$} \\
\hline & Std. coeff. & $T$ & $p$ & Std. coeff. & $T$ & $p$ \\
\hline Total precipitation & 0.682 & 3.047 & 0.003 & 0.838 & 3.829 & $<0.001$ \\
\hline SD total precipitation & -0.531 & -2.926 & 0.004 & -0.544 & -3.068 & 0.003 \\
\hline Max. water deficit & 0.574 & 3.333 & 0.001 & 0.499 & 2.962 & 0.004 \\
\hline Length of dry season & 1.451 & 4.546 & $<0.001$ & 1.54 & 4.934 & $<0.001$ \\
\hline \multirow[t]{2}{*}{ TRMM data } & \multicolumn{3}{|c|}{ Margin } & & & \\
\hline & Std. coeff. & $T$ & $p$ & & & \\
\hline Total precipitation & 0.306 & 1.259 & 0.211 & & & \\
\hline SD total precipitation & -0.001 & -0.78 & 0.437 & & & \\
\hline Max. water deficit & -0.273 & -1.319 & 0.19 & & & \\
\hline Length of dry season & 0.303 & 0.834 & 0.406 & & & \\
\hline
\end{tabular}

that the central and northwest regions contain a higher proportion of trees with relatively narrower leaves (mesophyll and above) defies simple explanation. Across broader environmental gradients (e.g. those traversing biomes), narrow leaves are typically associated with drier conditions, but in the current study the southwest region is considered as the driest. This seemingly contradictory finding may simply reflect the crude characterization of four vast and variable areas of the Amazon. Alternatively, other biophysical factors may be responsible for driving lamina shape across the basin.

\subsection{Environmental correlates}

A more direct way of assessing the influence of environmental variables on lamina shape metrics is through spatially corrected regressions. In the present study, such analysis was performed using both precipitation and soil fertility measurements. A range of significant correlations was found between the proportion of (relatively) narrower leaves and all four precipitation variables - total precipitation, standard deviation of total precipitation, water deficit, and length of the dry season. Significantly, these correlations remained when leaf size was controlled.

However, like the regional patterns, these results defy simple explanation because, taken at face value, they point towards a potential ecological role for narrower leaves in both drought conditions and in times of high water availability. Interestingly, this is concordant with the recent study of Yates et al. (2008, p. 383) in South Africa who suggest that the "small boundary layer associated with narrows leaves (of Fynbos plants) enables higher transpiration rates when water is plentiful" thereby enhancing the uptake of nutrients, while also having the "benefit of improved coupling of leaf to ambient temperature during the summer drought period". With regard to this last point, narrow leaves can be maintained close to ambient temperature without substantial transpiration (Gibson, 1998) - unlike broader leaves that lose heat through evaporative cooling in warm, dry conditions.

The existence of strong regional patterns of occurrence and a relationship with several precipitation variables suggests that leaf narrowness in large-leaved rainforest trees may indeed have a strong ecological function. However, the evidence does not support the hypothesis that, in this particular context, narrow leaves are an adaptation to dry conditions. Resolution of this fascinating observation, along with the finding that dry season length and total precipitation both appear to act in the same direction, will require more detailed experimental work on the ecological and physiological significance of differences in length-width lamina ratios. It is quite possible that leaf width has more than one ecological function and, like other leaf traits, is subject to various tradeoffs with other aspects of leaf, branch and tree phenotypic characteristics.

The potential role of narrower leaves in adapting trees to areas of low soil fertility has some limited support in the observed correlations between some of the quantitative leaf shape metrics and plot-based measurements of soil fertility. The proportion of trees with broad leaves was positively correlated with soil fertility and there was a significant negative correlation between the compound index of leaf shape and soil fertility. A lower score on the compound index means that there are relatively more trees in the broad leaf category than the narrow leaf category within a plot - thus, as soil fertility increases the relative frequency of trees with narrow 
Table 6. Correlations results between leaf shape variables $\left(I_{1,2}\right.$, controlling for leaf size, and Margin) and soil fertility (sum of bases: a) and phosphorus:) b) and correlation results between MARGIN and temperature: c) All correlations adjusting for the number of degrees of freedom using the Dutilleul (1993) method. Non-significant results for phosphorus are omitted.

\begin{tabular}{|c|c|c|c|c|}
\hline & Pearson's $r$ & Pearson's $r F$ & $d f$ & $p$ \\
\hline \multicolumn{5}{|l|}{ a) Sum of bases variable } \\
\hline \multicolumn{5}{|l|}{$I_{1}$-length-width ratio with tip } \\
\hline$\%$ trees with index $\leq 1$ & 0.367 & 5.537 & 35.6 & 0.024 \\
\hline$\%$ trees with index $>1$ and $<3$ & -0.022 & 0.025 & 49.9 & 0.876 \\
\hline$\%$ trees with index $\geq 3$ & 0.014 & 0.01 & 50.9 & 0.922 \\
\hline$\%$ trees in $I_{1, b}$ & 0.311 & 4.617 & 33.6 & 0.066 \\
\hline$\%$ trees in $I_{1, n}$ & -0.26 & 3.12 & 28.1 & 0.164 \\
\hline$I_{1, \text { comp }}$ & -0.511 & 9.652 & 27.3 & 0.004 \\
\hline \multicolumn{5}{|l|}{$I_{2}$-length-width ratio without tip } \\
\hline$\%$ trees with index $\leq 1$ & 0.321 & 4.936 & 39.5 & 0.04 \\
\hline$\%$ trees with index $>1$ and $<3$ & -0.075 & 0.29 & 51.9 & 0.593 \\
\hline$\%$ trees with index $\geq 3$ & 0.066 & 0.189 & 52.9 & 0.632 \\
\hline$\%$ trees in $I_{2, b}$ & 0.458 & 7.43 & 27.9 & 0.011 \\
\hline$\%$ trees in $I_{2, n}$ & -0.243 & 1.567 & 25.04 & 0.222 \\
\hline$I_{2, \text { comp }}$ & -0.568 & 9.465 & 19.9 & 0.006 \\
\hline \multicolumn{5}{|l|}{ Others } \\
\hline Large leaves and $I_{1, n}$ & -0.317 & 2.64 & 23.7 & 0.117 \\
\hline Large leaves and $I_{2, n}$ & -0.36 & 2.949 & 19.81 & 0.102 \\
\hline$\%$ trees with non-entire margin & 0.041 & 0.062 & 37.5 & 0.805 \\
\hline \multicolumn{5}{|l|}{ b) Phosphorus variable } \\
\hline$I_{1, \mathrm{comp}}$ & -0.686 & 6.975 & 7.81 & 0.03 \\
\hline Large leaves and $I_{1, n}$ & -0.504 & 5.045 & 14.8 & 0.004 \\
\hline \multicolumn{5}{|c|}{ c) Correlation between margin and temperature $\left({ }^{\circ} \mathrm{C}\right)$ - BIOCLIM dataset } \\
\hline$\%$ non-entire leaves & -0.457 & 5.521 & $21(n=92)$ & 0.029 \\
\hline
\end{tabular}

leaves per plot decreases. This negative correlation persists even when we control for leaf size, a result that supports the hypothesis that relatively narrower leaves are an adaptation to low nutrient soils. However, once again this conclusion should be treated cautiously as similar variables did not produce significant correlations in the present study. Clearly, more focused studies are required to uncover this relationship.

The strongest and clearest pattern from this analysis is the finding that the proportion of trees possessing leaves with non-entire margins (dissected and toothed) is negatively correlated with mean annual temperature. This relationship is well known over large ecological and spatial scales and has been used as a reliable ecological indicator of past temperatures (Wilf, 1997). This adds support to the contention that "leaves make good thermometers" (Wilf, 1997, p. 373), even in tropical rainforests that show a remarkable conservatism in leaf form.

\section{Conclusions}

The evidence from this study provides weak support for the hypothesis that narrow leaves in rainforests are an adaptation to relatively dryer conditions and some support that narrow leaves confer an advantage on trees growing in low nutrient conditions. The former is perhaps unsurprising given that the well documented correlations between leaf size and shape and precipitation have been observed on much larger geographic scales. Although the plots in this study stretch over thousands of kilometres they do not incorporate different biomes. For example, if some forest plots from the Brazilian cerrado had been included in the analysis it is highly likely that a much stronger relationship between lamina shape and precipitation would have emerged.

Finally, it is also important to note that it is conceptually and practically difficult to distinguish between leaf adaptations to low rainfall and to low soil nutrients for at least four reasons (Cunningham et al., 1999). First, they may be similar 
because the typical physiological response to both environmental conditions is a slowing of growth. Second, nutrientlimited soils can slow root growth, leading in turn to limited access to water. Third, nutrients are only available to plants if they are in solution, so low rainfall may restrict the supply of nutrients to a plant. Finally, slow growth rates of leaves leave them open to attack by herbivores, which may need to be countered by increased investment in defensive structures or changes in shape.

On the other hand, the study provides strong evidence that lamina shape has distinct regional patterns and that it is associated, although weakly, with a range of precipitation variables. Furthermore, this study supports the well-known association between leaf margin form and temperature - a macrogeographic association replicated in a tropical rainforest. These findings suggest that we still have a lot to learn about the adaptive function of different leaf characteristics in tropical rainforests and that the study of macrogeographic variation has the potential to challenge accepted theories and generate new ideas about the relationship between leaves and their environment.

Acknowledgements. A. Malhado's PhD was funded by Oxford University's Clarendon and Overseas Research Scheme award (ORS) scholarships. We thank I. Kühn for advice about spatial analyses; M. Ladle for comments and copy-editing; C. Vriesendorp, D. Pauletto, F. Borchsenius, B. M. Thiers, and L. Willemse have provided herbaria data.

Edited by: J. Lloyd

\section{References}

Bongers, F. and Popma, J.: Leaf characteristic of the tropical rainforest flora of Los Tuxtlas, Mexico, Bot. Gaz., 151, 345-365, 1990.

Borcard, D., Legendre, P., Avois-Jacquet, C., and Tuomisto, H.: Dissecting the spatial structure of ecological data at multiple scales, Ecology, 85, 1826-1832, 2004.

Brown, V. K., Lawton, J. H., and Grubb, P. J.: Herbivory and the evolution of leaf size and shape, Philos. T. Roy. Soc. B, 333, 265-272, 1991.

Cunningham, S. A., Summerhayes, B., and Westoby, M.: Evolutionary divergences in leaf structure and chemistry, comparing rainfall and soil nutrient gradients, Ecol. Monogr., 69, 569-588, 1999.

Dengler, N. and Kang, J.: Vascular patterning and leaf shape, Curr. Opin. Plant Biol., 4, 50-56, 2001.

Diniz-Filho, J. A. F. and Bini, L. M.: Modelling geographical patterns in species richness using eigenvector-based spatial filters, Global Ecol. Biogeogr., 14, 177-185, 2005.

Dormann, C. F., McPherson, J. M., Araújo, M. B., Bivand, R., Bolliger, J., Carl, G., Davies, R. G., Hirzel, A., Jetz, W., Kissling, W. D., Kühn, I., Ohlemüller, R., Peres-Neto, P. R., Reineking, B., Schröder, B., Schurr, F. M., and Wilson, R.: Methods to account for spatial autocorrelation in the analysis of species distributional data: a review, Ecography, 30, 609-628, 2007.
Dutilleul, P.: Modifying the t-test for assessing the correlation between 2 spatial processes, Biometrics, 49, 305-314, 1993.

Fonseca, C. R., Overton, J. M., Collins, B., and Westoby, M.: Shifts in trait-combinations along rainfall and phosphorus gradients, J. Ecol., 88, 964-977, 2000.

Gentry, A. H.: A Field Guide to the Families and Genera of Woody Plants of Northwest South America (Colombia, Ecuador, Peru) with Supplementary Notes on Herbaceous Taxa, The University of Chicago Press, Chicago, US, 1996.

Gibson, A. C.: Photosynthetic organs of desert plants, BioScience, 48, 911-920, 1998.

Givnish, T. J.: On the adaptive significance of compound leaves, with particular reference to tropical trees, in: Tropical Trees as Living Systems, Cambridge University Press, Cambridge, UK, 351-380, 1978.

Givnish, T. J.: On the adaptive significance of leaf form, in: Topics in Plant Population Biology, Columbia University Press, New York, US, 375-407, 1979.

Givnish, T. J.: Leaf and canopy adaptations in tropical forests, in: Physiological Ecology of Plants in the Wet Tropics, Junk, The Hague, Netherlands, 51-58, 1984.

Givnish, T. J.: Comparative studies of leaf form - assessing the relative roles of selective pressures and phylogenetic constraints, New Phytol., 106, 131-160, 1987.

Givnish, T. J. and Vermeij, G. J.: Sizes and shapes of liana leaves, Am. Nat., 975, 743-778, 1976.

Horn, H. S.: The Adaptive Geometry of Trees, Princetown University Press, Princetown, US, 1971.

Kessler, S. and Sinha, N.: Shaping up: the genetic control of leaf shape, Curr. Opin. Plant Biol., 7, 65-72, 2004.

Krieger, J. D., Guralnick, R. P., and Smith, D. M.: Generating empirically determined, continuous measures of leaf shape for paleoclimate reconstruction, Palaios, 22, 212-219, 2007.

Leaf Architecture Working Group: Manual of Leaf Architecture, Smithsonian Institution, Washington, US, 1999.

Legendre, P. and Legendre, L.: Numerical Ecology, 2nd edition, Elsevier, London, UK, 1998.

Leigh, E. G.: Structure and climate in tropical rain forest, Annu. Rev. Ecol. Syst., 6, 67-86, 1975.

Lloyd, J. and Farquhar, G. D.: Effects of rising temperatures and $\left[\mathrm{CO}_{2}\right]$ on the physiology of tropical forest trees, Philos. T. Roy. Soc. B, 363, 1811-1817, 2008.

Malhado, A. C. M., Malhi, Y., Whittaker, R. J., Ladle, R. J., ter Steege, H., Phillips, O. L., Butt, N., Aragão, L. E. O. C., Quesada, C. A., Araujo-Murakami, A., Arroyo, L., Peacock, J., Lopez-Gonzalez, G., Baker, T. R., Anderson, L. O., Almeida, S., Higuchi, N., Killeen, T. J., Monteagudo, A., Neill, D., Pitman, N., Prieto, A., Salomão, R. P., Vásquez-Martínez, R., and Laurance, W. F.: Spatial trends in leaf size of Amazonian rainforest trees, Biogeosciences, 6, 1563-1576, 2009, http://www.biogeosciences.net/6/1563/2009/.

McDonald, P. G. M., Fonseca, C. R., Overtons, J., and Westoby, M.: Leaf-size divergence along rainfall and soil-nutrient gradients: is the method of size reduction common among clades?, Funct. Ecol., 17, 50-57, 2003.

Niinemets, Ü., Portsmuth, A., and Tobias, M.: Leaf shape and venation pattern alter the support investments within leaf lamina in temperate species: a neglected source of leaf physiological differentiation?, Funct. Ecol., 21, 28-40, 2007. 
Niklas, K. J.: The effect of leaf-lobing on the interception of direct solar radiation, Oecologia, 80, 59-64, 1997.

Peacock, J., Baker, T. R., Lewis, S. L., Lopez-Gonzalez, G., and Phillips, O. L.: The RAINFOR database: monitoring forest biomass and dynamics, J. Veg. Sci., 18, 535-542, 2007.

Pearcy, R. W. and Yang, W.: The functional morphology of light capture and carbon gain in the redwood forest understorey plant, Adenocaulon bicolor Hook, Funct. Ecol., 12, 543-552, 1998.

Pearcy, R. W., Muraoka, H., and Valladares, F.: Crown architecture in sun and shade environments: assessing function and trade-offs with a three-dimensional simulation model, New. Phytol., 166, 791-800, 2005.

Quesada, C. A., Lloyd, J., Schwarz, M., Patiño, S., Baker, T. R., Czimczik, C., Fyllas, N. M., Martinelli, L., Nardoto, G. B., Schmerler, J., Santos, A. J. B., Hodnett, M. G., Herrera, R., Luizão, F. J., Arneth, A., Lloyd, G., Dezzeo, N., Hilke, I., Kuhlmann, I., Raessler, M., Brand, W. A., Geilmann, H., Moraes Filho, J. O., Carvalho, F. P., Araujo Filho, R. N., Chaves, J. E., Cruz Junior, O. F., Pimentel, T. P., and Paiva, R.: Chemical and physical properties of Amazon forest soils in relation to their genesis, Biogeosciences Discuss., 6, 3923-3992, 2009,

http://www.biogeosciences-discuss.net/6/3923/2009/.

Rangel, T. F. L. V. B, Diniz-Filho, J. A. F., and Bini, L. M.: Towards an integrated computational tool for spatial analysis in macroecology and biogeography, Global Ecol. Biogeogr., 15, 321-327, 2006.

Raunkiaer, C.: The Life Forms of Plants and Statistical Plant Geography, Oxford University Press, Oxford, UK, 1934.

Ribeiro, J. E. L. S., Hopkins, M. J. G., Vicentin, A., Sothers, C. A., Costa, M. A. S., de Brito, J. M., de Souza, M. A. D., Martins, L. H. P., Lohmann, L. G., Assunção, P. A. C. L., Pereira, E. C., Mesquita, M. R., and Procópio, L. C.: Flora da Reserva Ducke: Guia de Identificação das Plantas Vasculares de uma Floresta de Terra-firme na Amazônia Central, INPA-DFID, Manaus, Brazil, 1999.

Richards, P. W.: Speciation in the tropical rain forest and the concept of the niche, Biol. J. Linn. Soc., 1, 149-153, 1969.

Rivero-Lynch, A. P., Brown, V. K., and Lawton, J. H.: The impact of leaf shape on the feeding preference of insect herbivores: experimental and field studies with Capsella and Phyllotreta, Philos. T. Roy. Soc. B, 351, 1671-1677, 1996.

Rodriguez, D., Keltjens, W. G., and Goudriaan, J.: Plant leaf area expansion and assimilate production in wheat (Triticum aestivum L.) growing under low phosphorus conditions, Plant Soil, 200, 227-240, 1998.
Royal Horticultural Society: The New Royal Horticultural Society Dictionary of Gardening, Volume 1 A-C, Palgrave MacMillan, London, UK, 1997.

Royer, D. L. and Wilf, P.: Why do toothed leaves correlate with cold climates? Gas exchange at leaf margins provides new insights into a classic paleotemperature proxy, Int. J. Plant Sci., 167, 11$18,2006$.

Schneider, J. V., Zipp, D., Gaviria, J., and Zizka, G.: Successional and mature stands in an upper Andean rain forest transect of Venezuela: do leaf characteristics of woody species differ?, J. Trop. Ecol., 19, 251-259, 2003.

Takenaka, A.: Effects of leaf blade narrowness and petiole length on the light capture efficiency of a shoot, Ecol. Res., 9, 109-114, 1994.

Traiser, C., Klotz, S., Uhl, D., and Mosbrugger, V.: Environmental signals from leaves - a physiognomic analysis of European vegetation, New Phytol., 166, 465-484, 2005.

ter Steege, H., Pitman, N., Sabatier, D., Castellanos, H., Van der Hout, P., Daly, D. C., Silveira, M., Phillips, O., VásquezMartínez, R, Van Andel, T., Duivenvoorden, J., de Oliveira, A. A., Ek, R., Lilwah, R., Thomas, R., Van Essen, J., Baider, C., Maas, P., Mori, S., Terborgh, J., Vargas, P. N., Mogollón, H., and Morawetz, W.: A spatial model of tree alpha-diversity and tree density for the Amazon, Biodivers. Conserv., 12, 2255-2277, 2003.

Turner, I. M.: The Ecology of Trees in the Tropical Rainforest, Cambridge University Press, Cambridge, UK, 2001.

Verdcourt, B. and Bridson, D.: Rubiaceae, Royal Botanic Gardens, Kew, East African Herbarium, CRC Press, UK, 1976.

Webb, L. J.: A physiognomic classification of Australian rain forests, J. Ecol., 47, 551-570, 1959.

Webb, L. J.: Environment relationships of the structural types of Australian rainforest vegetation, Ecology, 49, 296-311, 1968.

Wilf, P.: When are leaves good thermometers?, A new case for leaf margin analysis, Paleobiology, 73, 373-390, 1997.

Yates, M. J., Verboom, G. A., and Cramer, M. D.: The physiological importance of small leaf sizes in the Mediterranean-type ecosystem vegetation of the Cape Floristic Region, S. Afr. J. Bot., 74, 383-383, 2008. 